\title{
Evaluation of myocardial functions in pregnant women with speckle-tracking echocardiography
}

\author{
Selma Arı ${ }^{1} \odot$, Hasan Arı ${ }^{1}$, Mustafa Yllmaz $^{2} \odot$, Tahsin Bozat $^{1} \odot$ \\ ${ }^{1}$ Department of Cardiology, University of Health Sciences, Bursa Yüksek Ihtisas Training and Research Hospital, Bursa, Turkey \\ ${ }^{2}$ Department of Cardiology, Uludağ University School of Medicine, Bursa, Turkey
}

\begin{abstract}
Objectives: The speckle-tracking technique calculates the regional rate, the strain and the strain rate from twodimensional gray-scale visualizations. The aim of this study was to evaluate with speckle-tracking echocardiography the effects of the first, second and third trimesters of pregnancy on cardiac functions.

Methods: One hundred five voluntary pregnant and 35 healthy women of reproductive age were included in the study. For echocardiographic evaluations, the 111 highest-quality visualizations were chosen: 24 cases in the first trimester, 31 cases in the second trimester, 32 cases in the third trimester and 24 healthy women as a control group. Global longitudinal, radial, and circumferential strain, and left ventricular (LV) rotation and twist were evaluated by two-dimensional speckle tracking echocardiography.

Results: During pregnancy, the diameter, and volume of the left atrium, LV stroke volume, and the heart rate significantly increased beginning in the first trimester $(p<0.0125)$. The parameters of pulse-Doppler E velocity and tissue Doppler Em velocity significantly increased in the first trimester $(p<0.0125)$, whereas in the second and third trimester they decreased to control levels. Global longitudinal strain was significantly decreased in the third trimester of the pregnancy $(p<0.0125)$. Basal and apical LV rotation and twist were significantly increased in the third trimester of pregnancy $(p<0.0125)$. LV apical and basal reverse rotation rate were significantly increased in the first trimester of pregnancy $(p<0.0125)$.

Conclusions: In the third trimester global longitudinal strain decreased whereas LV rotation and twist increased. Speckle-tracking echocardiography may be used to evaluate the effects of pregnancy and that provide further data on cardiac functions.

Keywords: Strain, echocardiography, tissue Doppler imaging, pregnancy
\end{abstract}

D uring the process that includes pregnancy, birth and the period after birth, important cardiovascular changes occur [1]. The increase of the volume burden that happens during pregnancy, the increase of heart rate and the decrease of the vascular resistance constitute the principle changes that occur in the cardiovascular system. These changes happen gradually and have different effects on the heart at each trimester.

The echocardiographic examination is the most important technique used to evaluate the effects of pregnancy on the heart. The speckle tracking echocardiography (STE) technique calculates the regional rate, strain and strain rate from two-dimensional grayscale visualizations and is an angle-independent technique $[2,3]$. With the speckle-tracking technique, 
it is possible to measure the transverse displacement as well as the left ventricle longitudinal strain parameters in apical visualizations. This technique also allows us to evaluate the radial and circumferential displacements. The evaluation of radial and circumferential displacements enables the calculation of the rotation and twist of myocardium [4].

The goal of this study is to use STE to evaluate the effects of pregnancy on cardiac functions in the first, second and third trimesters.

\section{METHODS}

\section{Selection of Cases}

This study included 105 volunteers pregnant and 35 volunteer age-matched healthy women of reproductive age who applied to the Gynecology and Cardiology clinics of Bursa Yüksek İhtisas Traning and Research Hospital. The study was approved by the Bursa Yüksek İhtisas Traning and Research Hospital Ethics Committee.

A detailed history of all the cases was taken. After written informed consent was obtained the demographic details (such as the week of pregnancy and age) of the cases were registered, physical examinations were conducted, and heart rate and blood pressure were measured. After taking ECG, standard echocardiographic analysis was performed. Based on the standard echocardiography analysis, the 111 highest-quality images were used.

Exclusion criteria were hypertension, diabetes, coronary artery disease, valvular heart disease, pulmonary hypertension, heart failure, atrial fibrillation, thyroid function disorder, and multiple pregnancies.

The week of pregnancy was calculated by taking into consideration the last day of menstruation. The cases were separated into three trimesters according to their week of pregnancy. Echocardiography records from 24 women in the first trimester, 31 women in the second trimester and 32 women in the third trimester and, as the control group, 24 healthy women are taken. The echocardiographic records for the cases in the first trimester were taken between weeks 7 and 11 of pregnancy, for cases in the second trimester between weeks 20 and 24 and for cases in the third trimester between weeks 32 and 36.

\section{Echocardiographic Evaluation \\ Standard Echocardiography}

Transthoracic echocardiography was performed using an echocardiography machine (Vivid 7, GE Medical System, Horten, Norway) with subjects in the left lateral decubitus position. A variable-frequency phased-array transducer (2.5-3.5 MHz) was used for thoracic echocardiographic imaging. A routine standard echocardiographic examination was performed, which included measurements of LV systolic and diastolic dimensions, LV ejection fraction (EF), mitral inflow velocities and mitral annular velocities. LVEF was calculated using Teicholz's method [5]. Left atrium (LA) volume was estimated using biplane area length method and indexed to body-surface area. Stroke volume was calculated using " Left ventricular outflow tract (LVOT) VTI x Cross Sectional Area of the LVOT" formula. Peak early (E) and late (A) diastolic velocities of mitral inflow were measured using pulsed-wave Doppler imaging at the tip of the mitral valve leaflets. Systolic (Sm) as well as early (Em) and late (Am) diastolic mitral annular velocities were acquired at the septal and lateral annulus in the apical four-chamber view.

\section{D Strain Echocardiography}

Parasternal short-axis [apical, mid (level of the papillary muscle), and basal segments] and apical four-chamber, two-chamber, long-axis views of the LV were recorded at end-expiration (70 to 140 frames/s) and probe frequency (range 1.6 to $3.2 \mathrm{MHz}$ ). All measurement performed with simultaneous electrocardiography at a sweep speed of $50-100 \mathrm{~mm} / \mathrm{sec}$. Timing of aortic valve closure was assessed looking at the aortic valve motion in the long-axis apical view. To standardize short-axis image planes among the individuals, we identified the basal LV segment at the level of the mitral valve leaflet tips and the apical segment at the level just proximal to LV luminal obliteration at the end-systolic period. To obtain reliable LV 2D strain and rotation values, three consecutive heart beats were digitally saved in cine loop format for offline analysis with EchoPac BT 12 software (GE-Vingmed; Norway). LV endocardial borders were manually traced at the end-systolic phase, a second, larger, concentric circle was then automatically generated near the epicardium in order to include all the LV myocardium for STE analysis. 
The three apical views were used for global longitudinal strain measurements. Short-axis views were used for measurement of global radial strain, global circular strain, and rotation. Radial strain and circular strain were measured on the short-axis view obtained at the level of the mid-ventricle (papillary muscle). LV rotation was measured on the short-axis views obtained at basal and apical levels.

$\mathrm{LV}$ rotations, at the basal or apical short-axis planes were determined as the average angular displacement of six myocardial segments. Counterclockwise LV rotation as viewed from the apex is expressed as a positive value and clockwise LV rotation as a negative one. The LV twist was calculated as the net difference between apical and basal rotation. We also measured the peak rotation rates during ejection and reverse rotation rates during diastole. Peak positive rotation rate was measured as time to peak positive rotation velocity and peak reverse rotation rate was measured as time to peak reverse rotation velocity.

Image analysis was performed by two independent cardiologist who was not involved in the image acquisition and had no knowledge of other characteristics of cases.

Inter and intraobserver agreement of strain measurements were assessed in 20 randomly selected patients (five patients for each group) by two independent observers who analyzed the data blind to the other observer results. Intraobserver agreement was assessed by one observer who analyzed the 20 randomly selected patients twice, more than 15 days apart.

\section{Statistical Analysis}

SPSS (Statistical Package for the Social Sciences ver. 10.0, SPSS Inc, Chicago, Illinois, USA) software was used for all statistical analyses. The numerical variants are expressed as the average \pm standard deviation and the categorical variants as percentage. The normality of distribution of the averages in each group was evaluated with the Shapiro-Wilk test. Logarithmic conversion was applied for variants that did not show normal distribution, and all averages were compared by one-way ANOVA. In one-way ANOVA, the p values of parameters in each group were compared with the control group by using Dunnett's post-test. The categorical variants were compared with the chi- square test or with Fisher's exact test. Inter and intraobserver agreements were assessed with Pearson's correlation coefficients. Bonferroni correction was applied for $\mathrm{p}$-value when more than one group was compared, for four group comparison $p<0.0125$ value was accepted as significant. In standard statistical analysis, $p<0.05$ value was accepted as significant.

\section{RESULTS}

Among the cases whose visualization were recorded, the visualization of 111 cases were approved for evaluation ( 24 cases in the first trimester, 31 cases in the second trimester, 32 cases in the third trimester, 24 cases in the control group). The demographic characteristics and physical examination findings were compared between the pregnants and the control group. Heart rate gradually increased beginning in the first trimester, whereas systolic blood pressure (SBP) and diastolic blood pressure (DBP) gradually decreased $(p<0.001, p<0.001, p=0.004$, respectively) (Tables 1 and 2).

\section{Conventional and tissue Doppler echocardiography}

The comparing of the conventional echocardiography parameters, the diameter, and volume of the LA increased beginning in the first trimester of pregnancy, whereas the velocity of the mitral $\mathrm{E}$ wave and the E/A ratio gradually decreased during the advancement of pregnancy despite their increase in the first trimester ( $p<0.001, p<0.001, p=0.004$, respectively) (Tables 1 and 2). LV stroke volume increased beginning in the first trimester of pregnancy (Tables 1 and 2).

The comparing the tissue Doppler parameters, the velocities of the mitral lateral and medial Em velocity increased in the first trimester, but afterward, they decreased to the level of the control group ( $p<0.001$, $p<0.001$, respectively) (Tables 1 and 2). Tricuspid lateral $\mathrm{Sm}$ velocities increased in the first and second trimester, but it decreased to control levels in the third trimester $(p=0.001)$ (Tables 1 and 2).

\section{Left Ventricular Strain and Rotation}

Global longitudinal strain significantly decreased in the third trimester according to control $(p<0.001)$ (Tables 3 and 4). Global circular strain and global 
Table 1. Demographic and echocardiography characteristics (conventional and tissue Doppler parameters)

\begin{tabular}{|c|c|c|c|c|c|c|}
\hline Variant & 1st Trimester & 2st Trimester & 3st Trimester & Control & $F$ value & $p$ value \\
\hline Age (year) & $26 \pm 3.5$ & $26 \pm 3.8$ & $27 \pm 4.5$ & $27 \pm 3.7$ & 1.30 & 0.27 \\
\hline $\begin{array}{l}\text { Heart rate } \\
\text { (pulse/min) }\end{array}$ & $81.0 \pm 7.6$ & $81.0 \pm 5.1$ & $86.0 \pm 5.8$ & $78.0 \pm 7.1$ & 8.09 & $<0.001$ \\
\hline SBP (mmHg) & $122.5 \pm 9.6$ & $111.7 \pm 10.2$ & $104.3 \pm 9.3$ & $118.1 \pm 14.4$ & 15.42 & $<0.001$ \\
\hline DBP (mmHg) & $72.9 \pm 6.3$ & $67.9 \pm 5.8$ & $68.8 \pm 5.6$ & $72.5 \pm 7.9$ & 4.74 & 0.004 \\
\hline LVEDD (mm) & $46.21 \pm 3.72$ & $46.19 \pm 3.92$ & $46.61 \pm 2.94$ & $44.72 \pm 3.26$ & 1.44 & 0.23 \\
\hline LVESD (mm) & $28.64 \pm 4.53$ & $28.83 \pm 3.24$ & $29.93 \pm 3.21$ & $27.56 \pm 3.17$ & 2.19 & 0.09 \\
\hline Septum (mm) & $8.19 \pm 1.44$ & $8.23 \pm 1.36$ & $8.79 \pm 1.38$ & $8.21 \pm 1.05$ & 1.34 & 0.26 \\
\hline Posterior (mm) & $8.21 \pm 1.42$ & $8.35 \pm 1.08$ & $8.67 \pm 1.09$ & $0.82 \pm 0.89$ & 0.96 & 0.41 \\
\hline EF (\%) & $66.50 \pm 8.85$ & $66.00 \pm 6.58$ & $64.37 \pm 6.24$ & $67.58 \pm 7.87$ & 0.93 & 0.42 \\
\hline Stroke volume (ml) & $54.87 \pm 4.65$ & $56.14 \pm 8.78$ & $58.75 \pm 5.39$ & $48.65 \pm 4.77$ & 5.79 & 0.009 \\
\hline $\begin{array}{l}\text { Left atrium volume } \\
\text { index }\left(\mathrm{ml} / \mathrm{m}^{2}\right)\end{array}$ & $25.81 \pm 3.12$ & $30.71 \pm 2.15$ & $32.19 \pm 2.43$ & $23.69 \pm 3.43$ & 6.78 & $<0.001$ \\
\hline Left atrium (cm) & $3.43 \pm 0.34$ & $3.58 \pm 0.32$ & $3.62 \pm 0.30$ & $3.26 \pm 0.35$ & 6.44 & $<0.001$ \\
\hline PASP (mmHg) & $25.69 \pm 7.76$ & $26.78 \pm 6.59$ & $27.42 \pm 9.38$ & $25.55 \pm 4.73$ & 1.21 & 0.87 \\
\hline E velocity $(\mathrm{cm} / \mathrm{s})$ & $109.14 \pm 35.27$ & $98.32 \pm 20.15$ & $82.65 \pm 21.37$ & $87.66 \pm 14.42$ & 6.81 & $<0.001$ \\
\hline A velocity $(\mathrm{cm} / \mathrm{s})$ & $72.23 \pm 31.45$ & $67.56 \pm 20.54$ & $68.42 \pm 17.27$ & $59.31 \pm 12.18$ & 1.37 & 0.25 \\
\hline E/A ratio & $1.59 \pm 0.35$ & $1.46 \pm 0.40$ & $1.24 \pm 0.35$ & $1.51 \pm 0.34$ & 4.74 & 0.004 \\
\hline $\begin{array}{l}\text { Mitral lateral Sm } \\
(\mathrm{cm} / \mathrm{s})\end{array}$ & $10.24 \pm 2.32$ & $9.34 \pm 2.42$ & $9.65 \pm 1.74$ & $10.43 \pm 2.27$ & 0.69 & 0.55 \\
\hline $\begin{array}{l}\text { Mitral Lateral Em } \\
(\mathrm{cm} / \mathrm{s})\end{array}$ & $20.13 \pm 3.15$ & $17.21 \pm 3.43$ & $15.27 \pm 3.22$ & $17.36 \pm 3.31$ & 7.49 & $<0.001$ \\
\hline $\begin{array}{l}\text { Mitral lateral Am } \\
(\mathrm{cm} / \mathrm{s})\end{array}$ & $8.78 \pm 2.85$ & $9.87 \pm 1.65$ & $10.15 \pm 1.27$ & $9.32 \pm 2.29$ & 1.48 & 0.22 \\
\hline $\begin{array}{l}\text { Mitral medial Sm } \\
(\mathrm{cm} / \mathrm{s})\end{array}$ & $10.56 \pm 1.42$ & $9.75 \pm 1.68$ & $9.72 \pm 1.76$ & $9.45 \pm 1.27$ & 2.71 & 0.04 \\
\hline $\begin{array}{l}\text { Mitral medial Em } \\
(\mathrm{cm} / \mathrm{s})\end{array}$ & $15.98 \pm 3.42$ & $14.34 \pm 3.67$ & $11.76 \pm 2.32$ & $12.34 \pm 2.27$ & 11.56 & $<0.001$ \\
\hline $\begin{array}{l}\text { Mitral medial Am } \\
(\mathrm{cm} / \mathrm{s})\end{array}$ & $9.75 \pm 1.27$ & $10.42 \pm 2.25$ & $10.76 \pm 2.45$ & $10.69 \pm 3.38$ & 2.25 & 0.08 \\
\hline $\begin{array}{l}\text { Tricuspid lateral } \\
\mathrm{Sm}(\mathrm{cm} / \mathrm{s})\end{array}$ & $16.47 \pm 3.78$ & $16.85 \pm 2.36$ & $14.65 \pm 2.53$ & $14.17 \pm 2.76$ & 6.19 & 0.001 \\
\hline $\begin{array}{l}\text { Tricuspid lateral } \\
\operatorname{Em}(\mathrm{cm} / \mathrm{s})\end{array}$ & $18.78 \pm 4.47$ & $19.85 \pm 3.47$ & $17.93 \pm 4.54$ & $16.43 \pm 3.67$ & 3.34 & 0.02 \\
\hline $\begin{array}{l}\text { Tricuspid lateral } \\
\operatorname{Am}(\mathrm{cm} / \mathrm{s})\end{array}$ & $14.89 \pm 4.68$ & $16.68 \pm 5.87$ & $19.45 \pm 1.47$ & $14.38 \pm 4.21$ & 1.74 & 0.16 \\
\hline
\end{tabular}

$\mathrm{BMI}=$ body mass index, $\mathrm{SBP}=$ systolic blood pressure, $\mathrm{DBP}=$ diastolic blood pressure, $\mathrm{LVEDD}=$ left ventricle enddiastolic diameter, $\mathrm{LVESD}=$ left ventricle end-systolic diameter, $\mathrm{EF}=$ ejection fraction, $\mathrm{PASP}=$ Pulmonary artery systolic pressure 
Table 2. Comparison with Dunnett's test of pregnant and control groups (physical examination findings, conventional and tissue Doppler echocardiography parameters)

\begin{tabular}{|c|c|c|c|c|}
\hline Variant & (I) & (J) & $\begin{array}{c}\text { Average } \\
\text { difference } \\
(\mathbf{I}-\mathbf{J})\end{array}$ & $p$ value \\
\hline \multirow[t]{3}{*}{ Heart rate } & 1st Trimester & Control & $2.41 \pm 1.84$ & 0.41 \\
\hline & 2st Trimester & Control & $3.06 \pm 1.74$ & 0.48 \\
\hline & 3 st Trimester & Control & $7.87 \pm 1.72$ & $<0.001$ \\
\hline \multirow[t]{3}{*}{ SBP } & 1st Trimester & Control & $4.37 \pm 2.82$ & 0.27 \\
\hline & 2st Trimester & Control & $-6.35 \pm 2.84$ & 0.07 \\
\hline & 3st Trimester & Control & $-13.76 \pm 3.01$ & $<0.001$ \\
\hline \multirow[t]{3}{*}{ DBP } & 1st Trimester & Control & $0.46 \pm 1.74$ & 0.98 \\
\hline & 2st Trimester & Control & $-3.95 \pm 1.86$ & 0.08 \\
\hline & 3st Trimester & Control & $-4.59 \pm 1.75$ & 0.02 \\
\hline \multirow[t]{3}{*}{ Left atrium } & 1st Trimester & Control & $0.17 \pm 0.09$ & 0.18 \\
\hline & 2st Trimester & Control & $0.31 \pm 0.09$ & 0.002 \\
\hline & 3st Trimester & Control & $0.35 \pm 0.08$ & $<0.001$ \\
\hline \multirow[t]{3}{*}{ Left atrium volume index } & 1st Trimester & Control & $2.12 \pm 0.03$ & 0.08 \\
\hline & 2st Trimester & Control & $6.98 \pm 1.02$ & 0.001 \\
\hline & 3 st Trimester & Control & $7.95 \pm 1.15$ & $<0.001$ \\
\hline \multirow[t]{3}{*}{ LV stroke volume } & 1st Trimester & Control & $6.20 \pm 1.05$ & 0.04 \\
\hline & 2st Trimester & Control & $7.11 \pm 2.19$ & 0.002 \\
\hline & 3 st Trimester & Control & $8.32 \pm 2.43$ & $<0.001$ \\
\hline \multirow[t]{3}{*}{ E velocity } & 1st Trimester & Control & $0.21 \pm 0.06$ & 0.005 \\
\hline & 2st Trimester & Control & $0.10 \pm 0.06$ & 0.26 \\
\hline & 3st Trimester & Control & $-0.05 \pm 0.06$ & 0.73 \\
\hline \multirow[t]{3}{*}{ E/A ratio } & 1st Trimester & Control & $0.08 \pm 0.10$ & 0.77 \\
\hline & 2st Trimester & Control & $-0.04 \pm 0.10$ & 0.93 \\
\hline & 3st Trimester & Control & $-0.26 \pm 0.09$ & 0.23 \\
\hline \multirow{3}{*}{$\begin{array}{l}\text { Mitral } \\
\text { lateral Em }\end{array}$} & 1st Trimester & Control & $0.03 \pm 0.01$ & 0.01 \\
\hline & 2st Trimester & Control & $0.006 \pm 0.01$ & 0.83 \\
\hline & 3 st Trimester & Control & $-0.001 \pm 0.009$ & 0.25 \\
\hline \multirow{3}{*}{$\begin{array}{l}\text { Mitral } \\
\text { medial Em }\end{array}$} & 1st Trimester & Control & $0.02 \pm 0.008$ & 0.004 \\
\hline & 2st Trimester & Control & $0.01 \pm 0.007$ & 0.12 \\
\hline & 3st Trimester & Control & $0.01 \pm 0.007$ & 0.12 \\
\hline \multirow{3}{*}{$\begin{array}{l}\text { Tricuspid } \\
\text { lateral Sm }\end{array}$} & 1st Trimester & Control & $0.01 \pm 0.007$ & 0.03 \\
\hline & 2st Trimester & Control & $0.02 \pm 0.007$ & 0.003 \\
\hline & 3st Trimester & Control & $0.001 \pm 0.007$ & 0.99 \\
\hline
\end{tabular}

$\mathrm{BMI}=$ body mass index, $\mathrm{SBP}=$ systolic blood pressure, $\mathrm{DBP}=$ Diastolic blood pressure 
Table 3. Evaluation of the left ventricular global strain and rotation with speckle-tracking

\begin{tabular}{lcccccc}
\hline Variant & $\begin{array}{c}\text { 1st } \\
\text { Trimester }\end{array}$ & $\begin{array}{c}\text { 2st } \\
\text { Trimester }\end{array}$ & $\begin{array}{c}\text { 3st } \\
\text { Trimester }\end{array}$ & Control & $\begin{array}{c}\text { F } \\
\text { value }\end{array}$ & p value \\
\hline $\begin{array}{l}\text { Global } \\
\text { longitudinal strain } \\
\text { (\%) }\end{array}$ & $-23.76 \pm 2.67$ & $-23.40 \pm 3.03$ & $-20.85 \pm 2.95$ & $-23,95 \pm 1.50$ & 7.53 & $<\mathbf{0 . 0 0 1}$ \\
$\begin{array}{l}\text { Global } \\
\text { circumferential } \\
\text { strain (\%) }\end{array}$ & $-22.99 \pm 2.75$ & $-23.50 \pm 3.35$ & $-23.09 \pm 4.65$ & $-26.13 \pm 4.53$ & 3.12 & $\mathbf{0 . 0 3}$ \\
\hline $\begin{array}{l}\text { Global radial } \\
\text { strain (\%) }\end{array}$ & $37.72 \pm 13.78$ & $39.27 \pm 10.23$ & $41.50 \pm 12.57$ & $40.19 \pm 6.21$ & 0.44 & 0.72 \\
\hline $\begin{array}{l}\text { Basal maximum } \\
\text { rotation (degree) }\end{array}$ & $-8.71 \pm 1.73$ & $-8.20 \pm 2.06$ & $-10.00 \pm 2.77$ & $-8.12 \pm 2.10$ & 3.91 & $\mathbf{0 . 0 1}$ \\
\hline $\begin{array}{l}\text { Apical maximum } \\
\text { rotation (degree) }\end{array}$ & $11.76 \pm 2.40$ & $12.33 \pm 4.20$ & $15.94 \pm 2.94$ & $14.00 \pm 3.98$ & 7.46 & $<\mathbf{0 . 0 0 1}$ \\
\hline $\begin{array}{l}\text { Twist (degree) } \\
\text { Basal rotation rate } \\
\text { (degree/sec) }\end{array}$ & $20.47 \pm 3.85$ & $20.54 \pm 5.60$ & $26.16 \pm 4.75$ & $22.19 \pm 5.58$ & 7.37 & $<\mathbf{0 . 0 0 1}$ \\
\hline $\begin{array}{l}\text { Apical rotation } \\
\text { rate (degree/sec) }\end{array}$ & $42.55 \pm 9.05$ & $47.13 \pm 16.47$ & $56.31 \pm 12.03$ & $49.79 \pm 18.12$ & 3.11 & $\mathbf{0 . 0 3}$ \\
\hline $\begin{array}{l}\text { Basal reversed } \\
\text { rotation rate } \\
\text { (degree/sec) }\end{array}$ & $42.86 \pm 13.01$ & $33.71 \pm 8.47$ & $35.29 \pm 7.34$ & $34.07 \pm 12.68$ & 4.16 & $\mathbf{0 . 0 0 8}$ \\
$\begin{array}{l}\text { Apical reversed } \\
\text { rotation rate } \\
\text { (degree/sec) }\end{array}$ & $65.47 \pm 15.44$ & $51.78 \pm 16.91$ & $49.06 \pm 12.86$ & $56.39 \pm 22.35$ & 3.54 & $\mathbf{0 . 0 1}$ \\
\hline & & & & & & \\
\hline
\end{tabular}

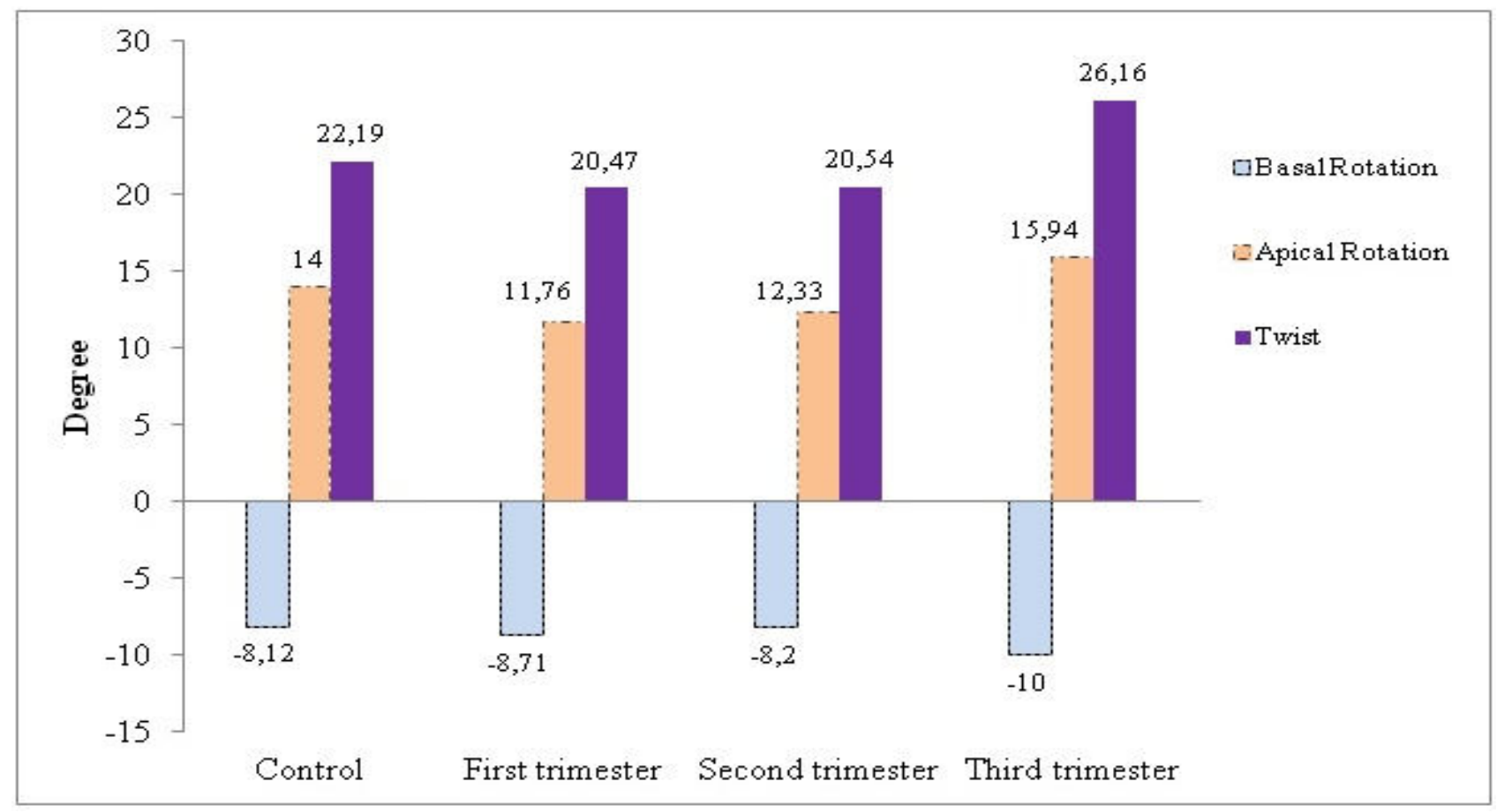

Fig. 1. Left ventricular rotation and twist. 
Table 4. Comparison of the cases and the control groups with the Dunnett's test (Speckle tracking parameters)

\begin{tabular}{|c|c|c|c|c|}
\hline Variant & (I) & $(J)$ & $\begin{array}{c}\text { Average Difference } \\
\text { (I - J) }\end{array}$ & $P$ Value \\
\hline \multicolumn{5}{|c|}{ Global longitudinal strain (\%) } \\
\hline & 1st Trimester & Control & $-0.19 \pm 0.82$ & 0.99 \\
\hline & 2st Trimester & Control & $-0.55 \pm 0.81$ & 0.82 \\
\hline & 3st Trimester & Control & $-3.09 \pm 0.78$ & $<0.001$ \\
\hline \multicolumn{5}{|c|}{ Basal maximum rotation (degree) } \\
\hline & 1st Trimester & Control & $0.53 \pm 0.65$ & 0.75 \\
\hline & 2st Trimester & Control & $0.02 \pm 0.64$ & 0.99 \\
\hline & 3st Trimester & Control & $1.82 \pm 0.62$ & 0.01 \\
\hline \multicolumn{5}{|c|}{ Apical maximum rotation (degree) } \\
\hline & 1st Trimester & Control & $-2.24 \pm 1.02$ & 0.07 \\
\hline & 2st Trimester & Control & $-1.67 \pm 1.00$ & 0.23 \\
\hline & 3st Trimester & Control & $1.93 \pm 0.98$ & 0.12 \\
\hline \multicolumn{5}{|c|}{ Twist (degree) } \\
\hline & 1st Trimester & Control & $-1.71 \pm 1.47$ & 0.51 \\
\hline & 2st Trimester & Control & $-1.65 \pm 1.44$ & 0.52 \\
\hline & 3st Trimester & Control & $3.97 \pm 1.42$ & 0.01 \\
\hline \multicolumn{5}{|c|}{ Basal reversed rotation rate } \\
\hline & 1st Trimester & Control & $8.78 \pm 3.08$ & 0.01 \\
\hline & 2st Trimester & Control & $-0.35 \pm 3.19$ & 0.99 \\
\hline & 3st Trimester & Control & $1.22 \pm 3.30$ & 0.96 \\
\hline \multicolumn{5}{|c|}{ Apical reversed rotation rate } \\
\hline & 1st Trimester & Control & $9.07 \pm 5.17$ & 0.20 \\
\hline & 2st Trimester & Control & $-4.61 \pm 5.22$ & 0.71 \\
\hline & 3st Trimester & Control & $-7.33 \pm 5.60$ & 0.42 \\
\hline
\end{tabular}

radial strain did not differ between pregnant and control (Table 3).

Basal maximal rotation significantly increased in the third trimester according to control $(p=0.01)$ (Tables 3 and 4) (Fig. 1). Apical maximal rotation significantly decreased at first $(11.76 \pm 2.40$ vs $15.94 \pm$ $2.94 ; p<0.001)$ and second trimester $(12.33 \pm 4.20 \mathrm{vs}$ $15.94 \pm 2.94 ; p=0.002)$ according to third trimester and control (Fig. 1). The twist degree significantly increased at the third trimester according to the first $(20.47 \pm 3.85$ vs $26.16 \pm 4.75 ; p=0.001)$, second (20.54 \pm 5.60 vs $26.16 \pm 4.75 ; p=0.001)$ trimester and control group $(22.19 \pm 5.58$ vs $26.16 \pm 4.75 ; p=0.01)$ (Tables 3 and 4) (Fig. 1). The rates of basal and apical reversed rotation rate increased in the early period of pregnancy ( $p=0.008, p=0.01$, respectively) (Table $3)$. Compared to the control group at each trimester, the rate of basal reversed rotation rate was significantly increased in the first trimester $(42.86 \pm 13.01$ vs $34.07 \pm 12.68, p=0.01$ ) (Table 4 ).

High interobserver correlation was found between the two observer measurements; global longitudinal strain $(\mathrm{r}=0.91 ; p=0.001)$, global radial strain $(\mathrm{r}=$ $0.90 ; p=0.001)$ and global circular strain $(\mathrm{r}=0.89 ; p$ $=0.002)$. Also high intraobserver agreement was found between the two measurement of the same operator, global longitudinal strain $(\mathrm{r}=0.93 ; p=$ $0.001)$, global radial strain $(\mathrm{r}=0.92 ; p=0.001)$ and 
global circular strain $(\mathrm{r}=0.92 ; p=0.001)$.

\section{DISCUSSION}

In this study, the diameter of the left atrium increased during pregnancy. The diastolic parameters of the pulse-Doppler and tissue Doppler increased in the first trimester, whereas they decreased to the control level during the second and third trimester. Global longitudinal strain decreased in the third trimester according to the first, second trimesters and control group. Left ventricular rotation and twist increased in the third trimester. Left ventricular reversed rotation rate increased in the first trimester.

When the parameters of conventional echocardiography were examined, the dimensions of the left atrium started to expand from the first trimester, reaching a maximum in the third trimester. Because left atrium volume increases during pregnancy, the venous return of the left atrium increases [6]. Because of the increased venous return, the dimension of the left atrium expands. Recently Tasar et al. [7] showed that left atrial area and volume increase whereas left atrial strain decrease from the first trimester to the third trimester during pregnancy. LV diameters increased during pregnancy but did not reach significance. However, the stroke volume increases significantly since the beginning of pregnancy. Increased stroke volume and heart rate provide the cardiac output increase that requires during pregnancy.

The pulse-Doppler images showed that the $\mathrm{E}$ wave velocity and E/A ratio increased in the first trimester and decreased afterward. Mitral lateral and medial tissue Doppler Em increased in the first trimester, in the second and third trimesters they gradually decreased. The compliance of the left ventricle, which decreases with the myocardial hypertrophy, is thought to be the most important factor responsible for these changes [8-11]. The increasing tricuspid Sm values reflect the contractility of the right ventricle, which increased in early pregnancy. These echocardiographic changes may explain with pregnancy-related preload increasing and left ventricular physiological myocardial hypertrophy. Previous studies have shown similar results $[10,12]$.

The quantitative assessment of global longitudinal is an important part of STE analysis. The longitudinal movement of the ventricular wall is one of the principal deformations of the heart, which represents as shortening and lengthening of myocardial fibers from the base to the apex. In this study, we found the ventricular global longitudinal strain decreased significantly in the third trimester of pregnancy. This is similar to the previous studies, [13, 14]. Although there are no significant changes in global radial and circular strain parameters during pregnancy, left ventricular rotation and twist values increase significantly in the 3rd trimester $[13,14]$. In the evaluation made in terms of the rotation rate, reversed rotation rate increased in the early period of pregnancy and decreased to control values in the last trimester of pregnancy.

Along with changes in systemic vascular resistance (afterload) and volume load (preload) during pregnancy, there are also changes in left ventricular dimensions and wall thicknesses. Together with these changes, the combination of changes in left ventricular deformation provides the necessary cardiac functions in pregnant women.

Despite the decrease in diastolic functions because of increasing volume burden and left ventricular mass during pregnancy, the systolic functions were protected. In spite of the decrease in longitudinal deformation, the necessary increase of stroke volume during pregnancy was provided with the increasing rotation and twist of the left ventricle. The increase in the left ventricle twist may be a systolic compensation mechanism. The increase in a myocardial twist has also been shown in patient groups who have concentric left ventricle hypertrophy and diastolic dysfunction related to age $[15,16]$. The findings of these studies support our results.

In our study, an increase of left ventricle early diastolic velocities and reversed rotation rate during the early period of pregnancy while in rotation degrees during the third trimester was observed. From these findings, we can conclude that the hemodynamic changes that appeared during pregnancy were compensated for with the augmentation of diastolic functions in early pregnancy and with the augmentation of systolic functions in the later period.

\section{Clinical recommendations}

The STE technique, which enables the evaluation of strain and rotational mechanics quantitatively will 
contribute to the understanding of what changing of myocardial function during pregnancy.

\section{Limitations}

There were some main limitations to this study: (1) small number of cases however the number of cases for each trimester is enough to prevent evaluation errors, (2) the fact that for each trimester group different patients were evaluated however evaluation of different pregnancies for each trimester can provide an overall average and better reflect the population, and (3) the fact that endocardial and epicardial rotations were not evaluated separately. These factors may affect myocardial functions.

\section{CONCLUSION}

In healthy pregnant, global longitudinal strain decreased whereas left ventricular rotation and twist increased in the third trimester. These additional quantitative data to standard echocardiographic methods provides us better understanding of the functional changes of myocardium during pregnancy.

\section{Conflict of interest}

The authors disclosed no conflict of interest during the preparation or publication of this manuscript.

\section{Financing}

The authors disclosed that they did not receive any grant during conduction or writing of this study.

\section{REFERENCES}

1. Clapp JF III, Capeless E. Cardiovascular function before, during and after the first and subsequent pregnancies. Am J Cardiol 1997;80:1469-73.

2. Amundsen BH, Helle-Valle T, Edvardsen T, Torp H, Crosby J, Lyseggen E, et al. Noninvasive myocardial strain measurement by speckle tracking echocardiography: validation against sonomicrometry and tagged magnetic resonance imaging. J Am Coll Cardiol 2006; 47:789-93.

3. Suffoletto MS, Dohi K, Cannesson M, Saba S, Gorcsan J 3rd. Novel speckle-tracking radial strain from routine black-and- white echocardiographic images to quantify dyssynchrony and predict response to cardiac resynchronization therapy. Circulation 2006;113:960-8.

4. Helle-Valle T, Crosby J, Edvardsen T, Lyseggen E, Amundsen $\mathrm{BH}$, Smith HJ, et al. New noninvasive method for assessment of left ventricular rotation: speckle tracking echocardiography. Circulation 2005;112:3149-56.

5. Teicholz LE, Kreulen T, Herman MW, Gorlin R. Problems in echocardiographic-angiographic correlations in the presence or absence of asynergy. Am J Cardiol 1976;37:7-11.

6. Moran AM, Colan SD, Mauer MB, Geva T. Adaptive mechanisms of left ventricular diastolic function to the physiologic load of pregnancy. Clin Cardiol 2002;25:124-31.

7. Tasar O, Kocabay G, Karagoz A, Kalayci Karabay A, Karabay CY, Kalkan S, et al. Evaluation of left atrial functions by 2dimensional speckle-tracking echocardiography during healthy pregnancy. J Ultrasound Med 2019;38:2981-8.

8. Kametas NA, McAuliffe F, Hancock J, Chambers J, Nicolaides KH. Maternal left ventricular mass and diastolic function during pregnancy. Ultrasound Obstet Gynecol 2001;18:460-6.

9. Mesa A, Jessurun C, Hernandez A, Adam K, Brown D, Vaughn WK, et al. Left ventricular diastolic function in normal human pregnancy. Circulation 1999;99:511-7.

10. Fok WY, Chan IY, Wong JT, Yu CM, Lau TK. Left ventricular diastolic function during normal pregnancy: assessment by spectral tissue Doppler imaging. Ultrasound Obstet Gynecol 2006;28:789-93.

11. Schannwell CM, Zimmermann T, Schneppenheim M, Plehn G, Marx R, Strauer BE. Left ventricular hypertrophy and diastolic dysfunction in healthy pregnant women. Cardiology 2002;97:73-8.

12. Bamfo JE, Kametas NA, Nicolaides KH, Chambers JB. Reference ranges for tissue Doppler measures of maternal systolic and diastolic left ventricular function. Ultrasound Obstet Gynecol 2007;29:414-20.

13. Savu O, Jurcuţ R, Giuşcă S, van Mieghem T, Gussi I, Popescu BA, et al. Morphological and functional adaptation of the maternal heart during pregnancy. Circ Cardiovasc Imaging 2012;5:289-97.

14. Cong J, Wang Z, Jin H, Wang W, Gong K, Meng Y, et al. Quantitative evaluation of longitudinal strain in layer-specific myocardium during normal pregnancy in China. Cardiovasc Ultrasound 2016;14:45.

15. Kim HK, Sohn DW, Lee SE, Choi SY, Park JS, Kim YJ, et al. Assessment of left ventricular rotation and torsion with twodimensional speckle tracking echocardiography. J Am Soc Echocardiogr 2007;20:45-53.

16. Mizuguchi Y, Oishi Y, Miyoshi H, Iuchi A, Nagase N, Oki T. Concentric left ventricular hypertrophy brings deterioration of systolic longitudinal, circumferential, and radial myocardial deformation in hypertensive patients with preserved left ventricular pump function. J Cardiol 2010;55:23-33. 